\title{
PRENATAL DEVELOPMENT OF GABAERGIC, GLYCINERGIC, AND DOPAMINERGIC NEURONS IN THE RABBIT RETINA ${ }^{1}$
}

\author{
SEK-CHUNG FUNG, ${ }^{2}$ YUN-CHEUNG KONG, AND DOMINIC MAN-KIT LAM ${ }^{3}$
}

Cullen Eye Institute and Program in Neuroscience, Baylor College of Medicine, Houston, Texas 77030 and Department of Biochemistry, Chinese University of Hong Kong and Kevin Hsu Research Foundation, Hong Kong

Received March 30, 1982; Revised June 3, 1982; Accepted June 4, 1982

\begin{abstract}
The main findings from our studies on the emergence and maturation of neurotransmitter systems in the rabbit retina are that, during normal development: (1) the commitments for certain neurons to become GABAergic, glycinergic, or dopaminergic are made prenatally; the maturation of these neurons, however, occurs postnatally; (2) specific accumulations of exogenously supplied transmitters by presumed retinal neurons were first observed autoradiographically around embryonic day 22 (E22) for $\gamma$-aminobutyric acid (GABA), E25 for glycine, and E27 for dopamine, suggesting that putative GABAergic, glycinergic, and dopaminergic neurons are determined phenotypically at least by these days; (3) based upon the three transmitter-specific properties-uptake, synthesis, and release-the uptake property is generally the first to emerge, while the appearance of the other properties follows a precise and distinct temporal pattern for each of the transmitters studied; (4) for GABAergic and glycinergic systems, the emergence of $\mathrm{K}^{+}$-stimulated, $\mathrm{Ca}^{2+}$-dependent release mechanisms occurs many days after the first appearance of the uptake properties; in contrast, the mechanisms for dopamine uptake and release emerge at about the same time; and (5) by our criteria, putative GABAergic and glycinergic amacrine cells are mature between postnatal day 10 (P10) and P12, around the time when the eyes first open and direction-selective ganglion cells can first be recorded; however, the dopaminergic neurons probably are not mature until about P24.
\end{abstract}

One of the characteristic features of neural differentiation is the emergence and maturation of specific neurotransmitter systems in different neurons. We have shown recently that certain transmitter-specific properties, such as uptake, synthesis, and release of the retinal neurotransmitters $\gamma$-aminobutyric acid (GABA), glycine, and dopamine, can be used as physiological and anatomical probes to follow the development of the vertebrate retina (Hollyfield et al., 1979; Lam et al., 1980, 1981; Kong et al., 1980; Rayborn et al., 1981; Sarthy et al., 1981). In particular, we found that, in the rabbit retina: (1) the

\footnotetext{
' We thank Ms. Patricia Glazebrook for technical assistance and Ms. Patricia Cloud for typing the manuscript. This work was supported by National Institutes of Health Grant EY02608 and a grant from the Retina Research Foundation (Houston). D. M. K. L. was the recipient of a Research Career Development Award from the United States National Eye Institute and a Olga K. Wiess Scholar Award from Research to Prevent Blindness, Inc., New York. Part of this work was done when D. M. K. L. was a Visiting Research Professor in Biochemistry at the Chinese University of Hong Kong

${ }^{2}$ Present address: University Laboratories of Physiology, Oxford University, Parks Road, OX1 3PT, England.

${ }^{3}$ To whom correspondence should be addressed at Cullen Eye Institute, Baylor College of Medicine, Houston, TX 77030.
}

commitments by certain neurons to use GABA, glycine, or dopamine as a neurotransmitter are made prenatally and (2) GABAergic, glycinergic, and dopaminergic neurons mature in distinctly different temporal patterns during postnatal retinal development (Lam et al., 1980, 1981; Kong et al., 1980). It was not known, however, whether the commitments by certain retinal neurons to GABA, glycine, or dopamine as neurotransmitters are made at different times during prenatal development. Since specific GABA-, glycine-, and dopamine-accumulating cells are present in the newborn rabbit retina, we have used transmitter-specific uptake and autoradiography as an anatomical probe to examine the emergence of putative GABAergic, glycinergic, and dopaminergic neurons in prenatal rabbit retinas. In addition, since newborn rabbit retinas possess a $\mathrm{K}^{+}$-stimulated, $\mathrm{Ca}^{2+}$-dependent mechanism for $\left[{ }^{3} \mathrm{H}\right]$ dopamine release (Lam et al., 1981), we also have examined the emergence of the dopamine release mechanism in prenatal retinas.

This is the fourth paper in our series of studies on the development of neurotransmitter systems in the rabbit retina. In this paper, we show by autoradiography that GABA-, glycine-, and dopamine-accumulating cells emerge at different times during the prenatal develop- 
ment of the rabbit retina and compare these results with the emergence and maturation of the mechanisms for the synthesis and release of these neurotransmitters.

\section{Materials and Methods}

Injections and incubations. Eight pregnant New England white (albino) rabbits were obtained from a local supplier (Nichols Rabbitry, Houston, TX) and used for this study. The precise dates of pregnancy were provided by the supplier and estimated to be \pm 1 day. The gestation period for these rabbits is $31 \pm 1$ days and the ages of the developing rabbits are designated by the traditional nomenclatures of $\mathrm{E}$ for embryonic (prenatal) days and $\mathrm{P}$ for postnatal days. Thus, E31 is equivalent to P0. At least three prenatal rabbits were uscd for each of the ages studied. For each experiment, the pregnant rabbit was tranquilized with ether and then anesthetized by intraperitoneal injections with Nembutal. Following abdominal incision, the uterus was opened and the embryos ( 7 to 10 per rabbit) were exposed while still attached to the uterus through the umbilical cord. The fused eyelid of each embryo was gently slit open with a razor blade to expose the eyes. About $10 \mu \mathrm{l}$ of mammalian Ringer's solution containing $10 \mu \mathrm{Ci}$ of either $\left[{ }^{3} \mathrm{H}\right] \mathrm{GABA},\left[{ }^{3} \mathrm{H}\right]$ glycine, or $\left[{ }^{3} \mathrm{H}\right]$ dopamine was injected into the vitreous of each eye through the corneal-scleral junction. The injection site could be visualized by observing through the lens the tip of the hypodermic needle. The radioactive compounds, purchased from New England Nuclear Corp., had the following specific activities: $\left[{ }^{3} \mathrm{H}\right] \mathrm{GABA}$, $39 \mathrm{Ci} / \mathrm{mmol} ;\left[{ }^{3} \mathrm{H}\right]$ glycine, $44 \mathrm{Ci} / \mathrm{mmol}$; and $\left[{ }^{3} \mathrm{H}\right]$ dopamine, $15.4 \mathrm{Ci} / \mathrm{mmol}$. Assuming that the volume of each embryonic eye was 0.2 to $0.4 \mathrm{ml}$, the initial concentrations of the labeled transmitters in the extracellular space was estimated to be 1 to $5 \mu \mathrm{M}$. Following the injections, the embryos were placed back in the uteri and the health of the anesthetized rabbit was kept under close observation. Ninety minutes after the injections, each injected eye from the embryos was enucleated and the retina was isolated. Each isolated retina was placed in a separate Petri dish containing Ames bicarbonate-buffered Ringer's solution ( $\mathrm{pH}$ 7.4; Ames and Pollen, 1969) oxygenated with $5 \% \mathrm{CO}_{2}, 95 \% \mathrm{O}_{2}$. After removal of all of the vitreous and the peripheral regions of the retinas, each retina was sectioned into five approximately equal pieshaped pieces and each was placed in a separate Petri dish containing $4 \mathrm{ml}$ of Ringer's solution.

Autoradiography. The autoradiographic procedure was similar to those reported earlier (Lam et al., 1980). After a 3-min wash in Ringer's solution, two pieces of retina from each injected eye were transferred to a fixative containing $2 \%$ glutaraldehyde and $1 \%$ paraformaldehyde in $150 \mathrm{~mm}$ sodium phosphate buffer $(\mathrm{pH} \mathrm{7.2)}$. The retina was fixed for $1 \mathrm{hr}$ at room temperature and overnight at $4{ }^{\circ} \mathrm{C}$, postfixed with $1 \% \mathrm{OsO}_{4}$, dehydrated with ethanol, and embedded in Epon/Araldite mixture. Sections, 1 to $2 \mu \mathrm{m}$ thick, were cut and placed on precleaned glass microscopic slides. Slides were dipped in the dark in Kodak NTB2 liquid emulsion (diluted 1:1 with water) at $40^{\circ} \mathrm{C}$. After 7 to 150 days of exposure at $4^{\circ} \mathrm{C}$ in the dark, the slides were developed for $2 \mathrm{~min}$ at $15^{\circ} \mathrm{C}$ in Kodak Dektol (diluted 1:1 with water) fixed with
Kodak fixer at $15^{\circ} \mathrm{C}$ for $15 \mathrm{~min}$. The autoradiographs then were washed with three changes of distilled water, stained with $1 \%$ toluidine blue, and examined by light microscopy to determine the presence and localization of $\left[{ }^{3} \mathrm{H}\right] \mathrm{GABA},\left[{ }^{3} \mathrm{H}\right]$ glycine, and $\left[{ }^{3} \mathrm{H}\right]$ dopamine uptake, respectively.

Release experiments. Three pieces of retina from each eye injected with $\left[{ }^{3} \mathrm{H}\right]$ dopamine were incubated at room temperature in a Petri dish containing $5 \mathrm{ml}$ of Ringer's solution for $1 \mathrm{hr}$. The medium was changed every $5 \mathrm{~min}$. In order to enhance the effective exchange between the extracellular fluid and the Ringer's solution, the Petri dishes were placed on a shaker set at a moderate speed. After $1 \mathrm{hr}$ of washing, the spontaneous efflux of radioactivity from each piece of retina usually reached a steady basal level. Each piece of retina then was transferred to a graduated conical tube containing either $2 \mathrm{ml}$ of normal Ringer's solution or an isotonic Ringer's solution in which $56 \mathrm{~mm} \mathrm{NaCl}$ had been replaced by $56 \mathrm{~mm}$ $\mathrm{KCl}\left(\mathrm{K}^{+}\right.$-rich) to examine the presence of $\mathrm{K}^{\prime}$-stimulated $\left[{ }^{3} \mathrm{H}\right]$ dopamine release. The medium in each tube was changed every $3 \mathrm{~min}$. One milliliter of each eluate was mixed thoroughly with $9 \mathrm{ml}$ of a scintillant mixture (667 $\mathrm{ml}$ of toluene, $333 \mathrm{ml}$ of Triton X-100, $5.5 \mathrm{gm}$ of PPO (2,5-diphenyloxazole), and $0.1 \mathrm{gm}$ of POPOP (1,4-bis-2(5-phenyloxazolyl)benzene)), and the radioactivity was measured by a liquid scintillation counter (Beckman, model LS-330). Ten microliters of each eluate was used to determine, by high voltage paper electrophoresis, the percentage of total radioactivity remaining as $\left[{ }^{3} \mathrm{H}\right]$ dopamine (Hildebrand et al., 1971). The $\mathrm{Ca}^{2+}$ dependence of this release was studied by adding $\mathrm{CoCl}_{2}$ to either normal or $\mathrm{K}^{+}$-rich Ringer's solution at a final concentration of $10 \mathrm{~mm}$ during the appropriate intervals. The $\mathrm{K}^{+}$-stimulated, $\mathrm{Ca}^{2+}$-dependent release of $\left[{ }^{3} \mathrm{H}\right]$ dopamine from the retina was expressed (in percent) as the ratio of total disintegrations per min of $\left[{ }^{3} \mathrm{H}\right]$ dopamine released into the medium due to $\mathrm{Co}^{2+}$-inhibited $\mathrm{K}^{+}$stimulation over the total disintegration per min of $\left[{ }^{3} \mathrm{H}\right]$ dopamine remaining in the retina at the time of the $\mathrm{K}^{+}$-induced release. After each release experiment, the retina was homogenized with a glass homogenizer (from Kontes Glass Co., Vineland, NJ) in $1 \mathrm{ml}$ of $40 \%$ trichloroacelic acid. Twenly microliters of the supernatant was used to determine the percentage of the total radioactivity in the retina remaining as $\left[{ }^{3} \mathrm{H}\right]$ dopamine using high voltage paper electrophoresis (Hildebrand et al., 1971).

In order to protect the $\left[{ }^{3} \mathrm{H}\right]$ dopamine from degradation, sodium ascorbate (from Merck) and pargyline hydrochloride (from Regis Chemical Co.) were added to all of the Ringer's solutions at final concentrations of $1 \mathrm{mM}$ and $15 \mu \mathrm{M}$, respectively.

\section{Results}

Transmitter uptake in adult and newborn retinas. Numerous investigators have demonstrated by autoradiography that exogenously supplied dopamine, glycine, and GABA are accumulated selectively by different subpopulations of amacrine cells in the adult rabbit retina (Fig. 1; Ehinger, 1970, 1977; Brunn and Ehinger, 1972; Ehinger and Floren, 1978; Brandon et al., 1979; Lam et al., 1980, 1981; Kong et al., 1980). Additionally, our pre- 

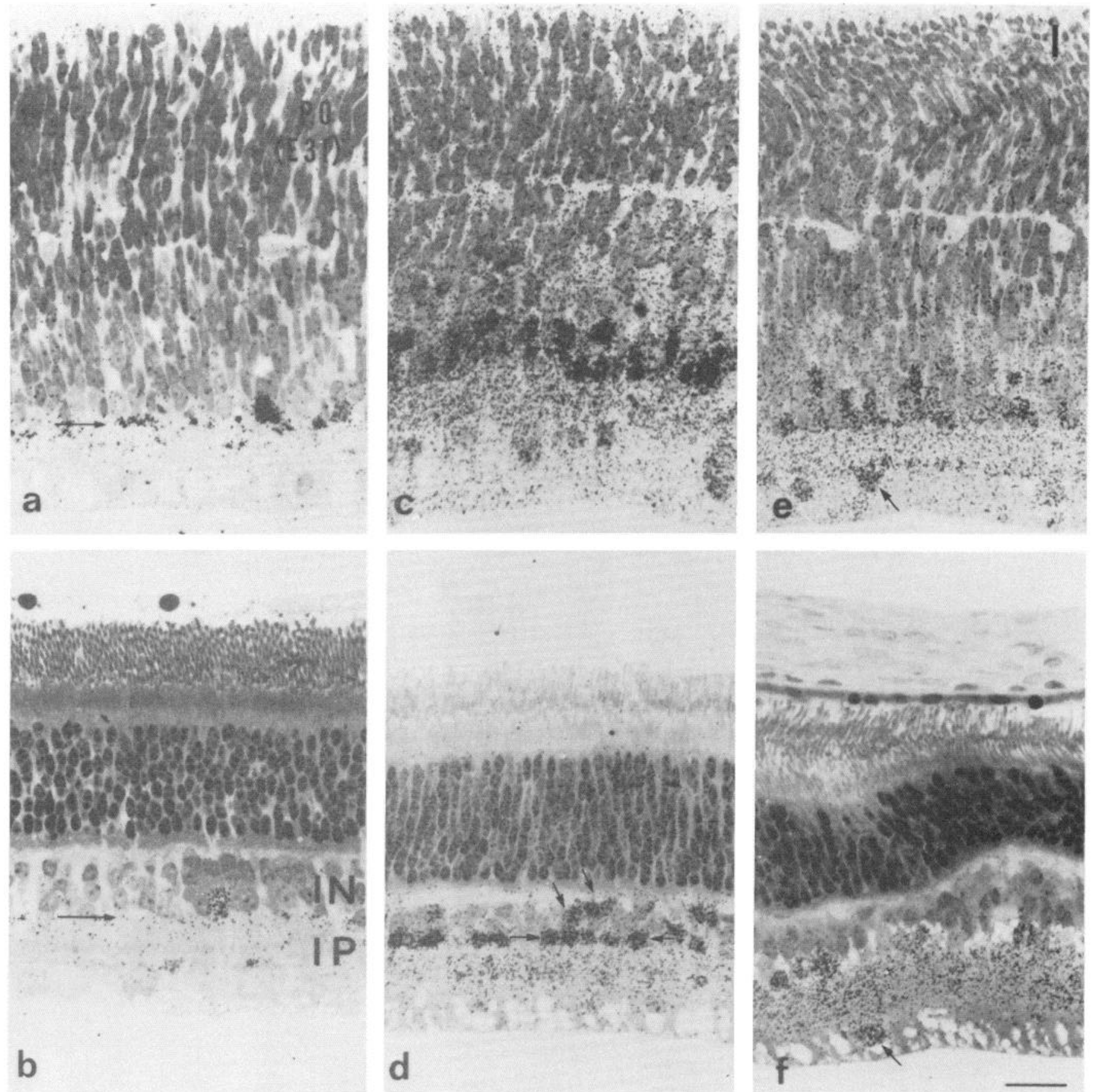

Figure 1. Autoradiographs of newborn $(a, c$, and $e)$ and adult $(b, d$, and $\mathrm{f})$ retinas following injections of $\left[{ }^{3} \mathrm{H}\right] \mathrm{dopamine}(a$ and $b),\left[{ }^{3} \mathrm{H}\right]$ glycine $(c$ and $d)$, and $\left[{ }^{3} \mathrm{H}\right] \mathrm{GABA}(e$ and $f)$, respectively, into rabbit eyes in vivo. IN, Inner nuclear layer; $I P$, inner plexiform layer; horizontal arrows on $a$ and $b$, layer 1 of the inner plexiform layer; horizontal arrows on $d$, presumed glycineaccumulating amacrine cells; oblique arrows on $d$, presumed bipolar cells; arrows on $e$ and $f$, GABA-accumulating somas in the ganglion cell layer. Scale bar, $20 \mu \mathrm{m}$.

vious results indicate that, on the basis of their locations, densities, and ramifications, certain cells in the newborn rabbit retina take up GABA, glycine, and dopamine, respectively (Fig. 1; Lam et al., 1980, 1981; Kong et al., 1980). Our findings also suggest that these cells probably will become putative GABAergic, glycinergic, and dopaminergic neurons, respectively, in the adult retina.

As reported elsewhere and summarized in Figure 1, the dopamine-accumulating cells in both newborn and adult retinas probably belong to a type of amacrine cell that ramifies mainly in layer 1 of the inner plexiform layer (horizontal arrow, Fig. 1, $a$ and $b$ ), with occasional punctate terminals deeper in the inner plexiform layer (Lam et al., 1981).

The glycine-accumulating cells, on the other hand, probably belong to several different types of amacrine cells (Fig. 1d, horizontal arrows) and at least one type of bipolar cell (Fig. 1d, oblique arrows; Kong et al., 1980). 

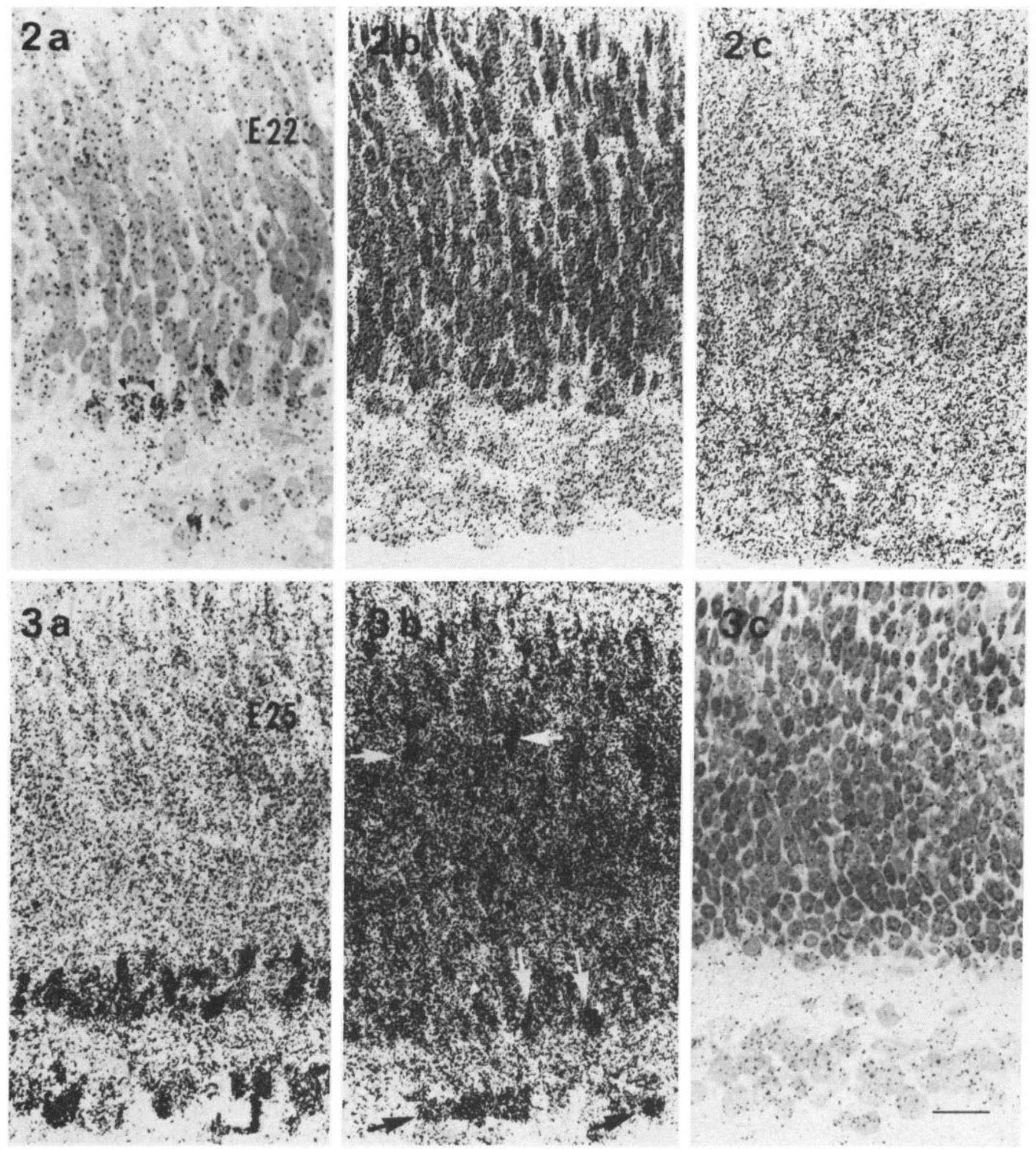

Figures 2 to 5. Autoradiographs of E22 (Fig. 2), E25 (Fig. 3), E27 (Fig. 4), and E29 (Fig. 5) retinas following injections of [ $\left.{ }^{3} \mathrm{H}\right]$ GABA $(a),\left[{ }^{3} \mathrm{H}\right]$ glycine $(b)$, and $\left[{ }^{3} \mathrm{H}\right]$ dopamine $(c)$, respectively, into rabbit eyes in vivo. Arrowheads on $2 a$, GABA-accumulating somas in the amacrine cell layer; white oblique arrows on $3 b$, glycine-accumulating cells in the amacrine cell layer; white horizontal arrows on $3 b$, heavily labeled somas in the ganglion cell layer; black arrow on $4 c$, dopamine-accumulating cell in the amacrine cell layer; white arrow on $4 c$, layer 1 of the inner plexiform layer. Scale bar, $20 \mu \mathrm{m}$.

It is likely that the glycine-accumulating amacrine cells take up glycine by a high affinity uptake mechanism (Chin and Lam, 1980; Kong et al., 1980). It is not known, however, whether the $\left[{ }^{3} \mathrm{H}\right]$ glycine in the glycine-accu- mulating bipolar cells represent active uptake by these cells or diffusion of $\left[{ }^{3} \mathrm{H}\right]$ glycine into these neurons from the glycine-accumulating amacrine cells. This is because, as we have reported previously (Kong et al., 1980), one 

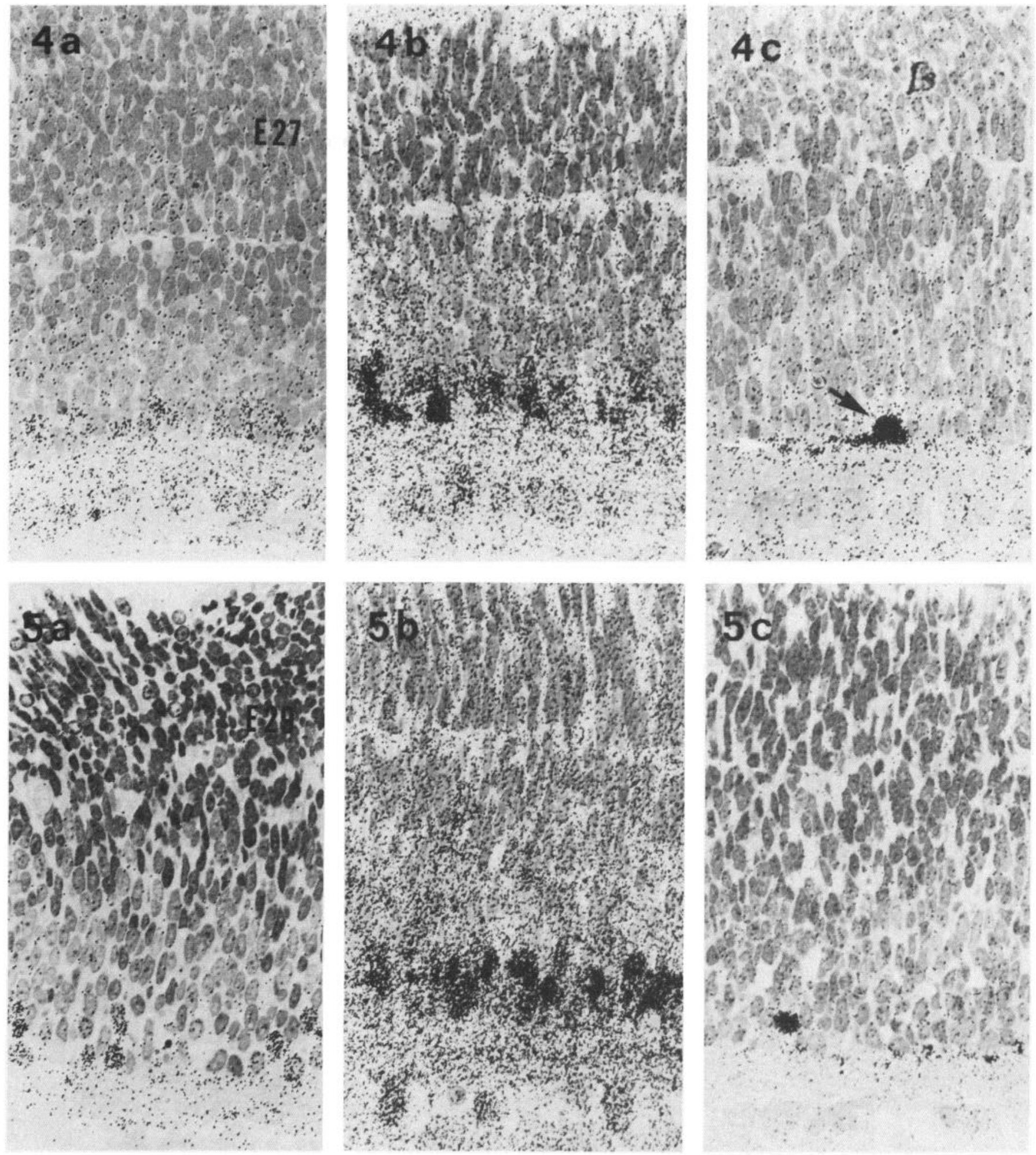

Figures 4 and 5

type of glycine-accumulating amacrine cell may be similar to the narrow field, bistratified (type II) amacrine cell of the cat retina described by Kolb and Famiglietti (1974; see also Kolb, 1979). Since these investigators have shown that this cell type makes extensive gap junctions with the terminals of certain cone bipolar cells and since glycine is probably capable of diffusing through gap junctions (Rieske et al., 1975), it is therefore possible that the presumed glycine-accumulating bipolar cells may not actually possess a high affinity glycine uptake mechanism but rather accumulate the $\left[{ }^{3} \mathrm{H}\right]$ glycine by diffusion. These two alternatives cannot be easily resolved by studies of the intact retina. Perhaps autoradiographic studies of glycine uptake in isolated retinal cells (Sarthy and Lam, 1979a) will eventually determine whether certain bipolar cells possess a high affinity mechanism for 
glycine uptake and whether they may be considered putative glycinergic neurons.

Similar to glycine-accumulating neurons, there are probably also several types of GABA-accumulating amacrine cells in the rabbit retina (Ehinger, 1970; Brandon et al., 1979, 1980; Lam et al., 1980). In addition, there is also at least one type of GABA-accumulating neuron with somas in the ganglion cell layer (arrows, Fig. 1, $e$ and $f$, Lam et al., 1980). We have shown by immunocytochemistry that the GABA-accumulating neurons probably also contain high levels of L-glutamic acid decarboxylase (Brandon et al., 1979, 1980), suggesting that these may be GABAergic neurons in the rabbit retina. Once again, similar to glycine- and dopamine-accumulating cells, GABA-accumulating cells can be clearly identified in the newborn retina (Fig. 1e), indicating that the commitments for certain cells to be GABAergic, glycinergic, or dopaminergic are all made prenatally in the rabbit retina.

Emergence of transmitter uptake in prenatal retinas. In view of the preceding finding, we examined the ontogeny of these transmitter systems in prenatal rabbit retinas. Since the endogenous levels of GABA and dopamine are low, whereas the uptake mechanisms appear to be mature, in the newborn retina (Lam et al., 1980, 1981; Kong et al., 1980), we began our studies by first determining autoradiographically the prenatal ages at which specific GABA, glycine, and dopamine uptake into certain retinal cells can be localized unequivocally. A possible shortcoming of this study is that it is only a qualitative evaluation and cannot distinguish or quantitatively measure the emergence and maturation of the different kinetic parameters, such as $K_{m}$ and $V_{\max }$, of the transport processes. Nevertheless, the autoradiographic approach does provide a morphological demonstration of the ontogenesis of transmitter accumulations in specific cells during retinal development.

The results of our autoradiographic studies on GABA, glycine, and dopamine accumulations in prenatal rabbit retinas are summarized in Figures 2 to 5 . The normal gestation period for the rabbit is $31 \pm 1$ days. We have adopted the traditional nomenclature of denoting $\mathrm{E}$ for embryonic (prenatal) days and $\mathrm{P}$ for postnatal days. To minimize variations in the onset and time of the gestation period among animals, the uptake studies of the different transmitters for a given embryonic day (E22, E25, etc.) are performed on the same animal or its siblings from the same mother.

The first day on which any specific transmitter uptake was observed was E22. On this day, even overexposure of autoradiographic sections from eyes injected with $\left[{ }^{3} \mathrm{H}\right]$ glycine or $\left[{ }^{3} \mathrm{H}\right]$ dopamine show only diffuse labeling; no specific accumulations of these transmitters by any retinal cells were observed in all of the animals studied (Fig. $2, b$ and $c$ ). On the contrary, autoradiographic sections of retinas from eyes injected with $\left[{ }^{3} \mathrm{H}\right] \mathrm{GABA}$ show that some somas in the amacrine cell layer selectively accumulate $\left[{ }^{3} \mathrm{H}\right]$ GABA (arrowheads, Fig. 2a). Although these GABA-accumulating cells are seen only occasionally and the label is generally weak, our observations suggest that a specific high affinity mechanism for GABA uptake probably is present in the rabbit retina around
E22, whereas those for glycine and dopamine uptake are not yet present at this time.

By E25, it is evident that, similar to the adult retina, certain cells in the amacrine and ganglion cell layers selectively accumulate $\left[{ }^{3} \mathrm{H}\right]$ GABA (Fig. $3 a$ ). In contrast, there is still little or no specific uptake of dopamine into retinal cells at this stage (Fig. $3 c$ ). The pattern of $\left[{ }^{3} \mathrm{H}\right]$ glycine uptake in E25 retinas is much less certain. Although it is clear that superimposed on the high background levels of radioactivity are heavily labeled somas in the amacrine and ganglion cells layers (oblique white and black arrows, respectively, Fig. $3 b$ ) resembling glycine-accumulating cells in the adult retina, some heavily labeled elongated somas also are found in the outer retina (horizontal white arrows, Fig. $3 b$ ). The identity of these somas are not known. They may represent a population of migrating retinal cells en route to their final destinations or they may be truly indicative of cells in the outer retina. Taken together, although we cannot state definitely that the glycine-accumulating cells in E25 retinas are the precursors of putative glycinergic neurons, our observations suggest that a high affinity mechanism for glycine accumulation is present around this time.

By E27, certain somas in the amacrine cell layer undoubtedly possess a specific high affinity mechanism for glycine accumulation (Fig. $4 b$ ). Additionally, we also observe, for the first time, the accumulation of $\left[{ }^{3} \mathrm{H}\right]$ dopamine by a cell type with somas in the amacrine cell
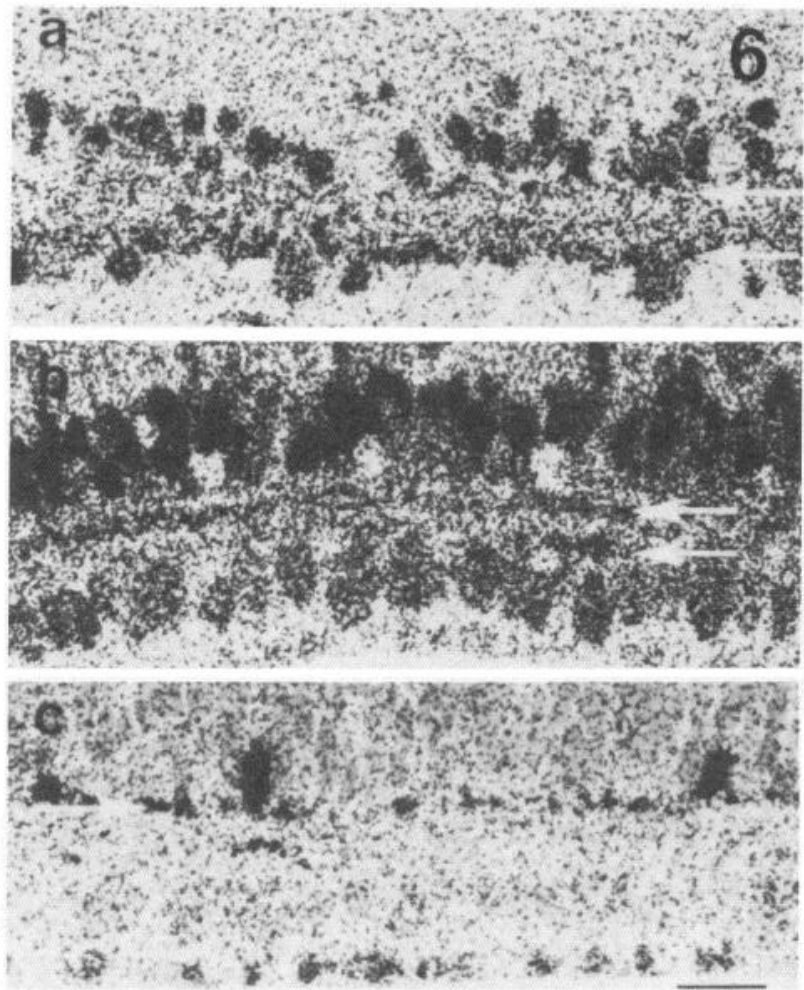

Figure 6. Overexposed autoradiographs of E29 retinas injected intraocularly with $\left[{ }^{3} \mathrm{H}\right] \mathrm{GABA}(a),\left[{ }^{3} \mathrm{H}\right]$ glycine $(b)$, and $\left[{ }^{3} \mathrm{H}\right]$ dopamine $(c)$, respectively. Horizontal arrows, Laminations of GABA-accumulating $(a)$, glycine-accumulating $(b)$, and dopamine-accumulating $(c)$ terminals in the inner plexiform layer. Scale bars, $20 \mu \mathrm{m}$. 
layer (black arrow, Fig. 4c) which ramify predominantly in layer 1 of the inner plexiform layer (white arrow, Fig. $4 c$ ). The morphology of this cell type is very similar to the dopamine-accumulating amacrine cells of the adult retina. We therefore conclude that the dopamine uptake mechanism first appears around this time and that the commitment by certain cells in the rabbit to become dopaminergic is made at least by E27.

By E29, the labeling patterns for GABA, glycine, and dopamine uptake are similar to those found in the newborn retina (Fig. 5). In particular, overexposed autoradiographic sections of E29 retinas incubated in vivo with $\left[{ }^{3} \mathrm{H}\right] \mathrm{GABA},\left[{ }^{3} \mathrm{H}\right] \mathrm{glycine}$, and $\left[{ }^{3} \mathrm{H}\right]$ dopamine, respectively, show that, within the inner plexiform layer, distinct laminations of the GABA-, glycine-, and dopamine-accumulating processes are evident (white arrows, Fig. 6, $a, b$, and $c$ ) by this day. Furthermore, the patterns of ramifications for the GABA-, glycine-, and dopamineaccumulating amacrine cells in E29 retinas are similar to those observed in the adult retina, suggesting a direct lineage or correspondence of these three transmitterspecific cell types between E29 and adult retinas.
Dopamine release in prenatal retinas. Our previous studies have shown that the contents and syntheses of GABA and dopamine as well as the $\mathrm{K}^{+}$-stimulated, $\mathrm{Ca}^{2+}$ dependent releases of preloaded $\left[{ }^{3} \mathrm{H}\right] \mathrm{GABA}$ and $\left[{ }^{3} \mathrm{H}\right]$ glycine are very low in the newborn retina (Lam et al., 1980; Kong et al., 1980). There is, however, a significant amount of $\mathrm{K}^{+}$-stimulated, $\mathrm{Ca}^{2+}$-dependent release of preloaded $\left[{ }^{3} \mathrm{H}\right]$ dopamine from the newborn retina (Lam et al., 1981). This observation led us to determine the emergence of the dopamine release mechanism in prenatal retinas. As prenatal retinas contain little or no endogenous dopamine (Lam et al., 1981), we made use of the existence of the high affinity dopamine uptake mechanism by E27 to first load the dopamine-accumulating cells with $\left[{ }^{3} \mathrm{H}\right]$ dopamine and subsequently examine the effects of high external $\mathrm{K}^{+}$on $\left[{ }^{3} \mathrm{H}\right]$ dopamine release. As shown in Figure 7 , detectable $\mathrm{K}^{+}$-stimulated, $\mathrm{Ca}^{2+}$-dependent release of preloaded dopamine can be observed as early as E27, a time at which specific $\left[{ }^{3} \mathrm{H}\right]$ dopamine uptake is first observed autoradiographically (Fig. 4c). Product identifications of the radioactivities in the retinas and eluates using high voltage paper electrophoresis

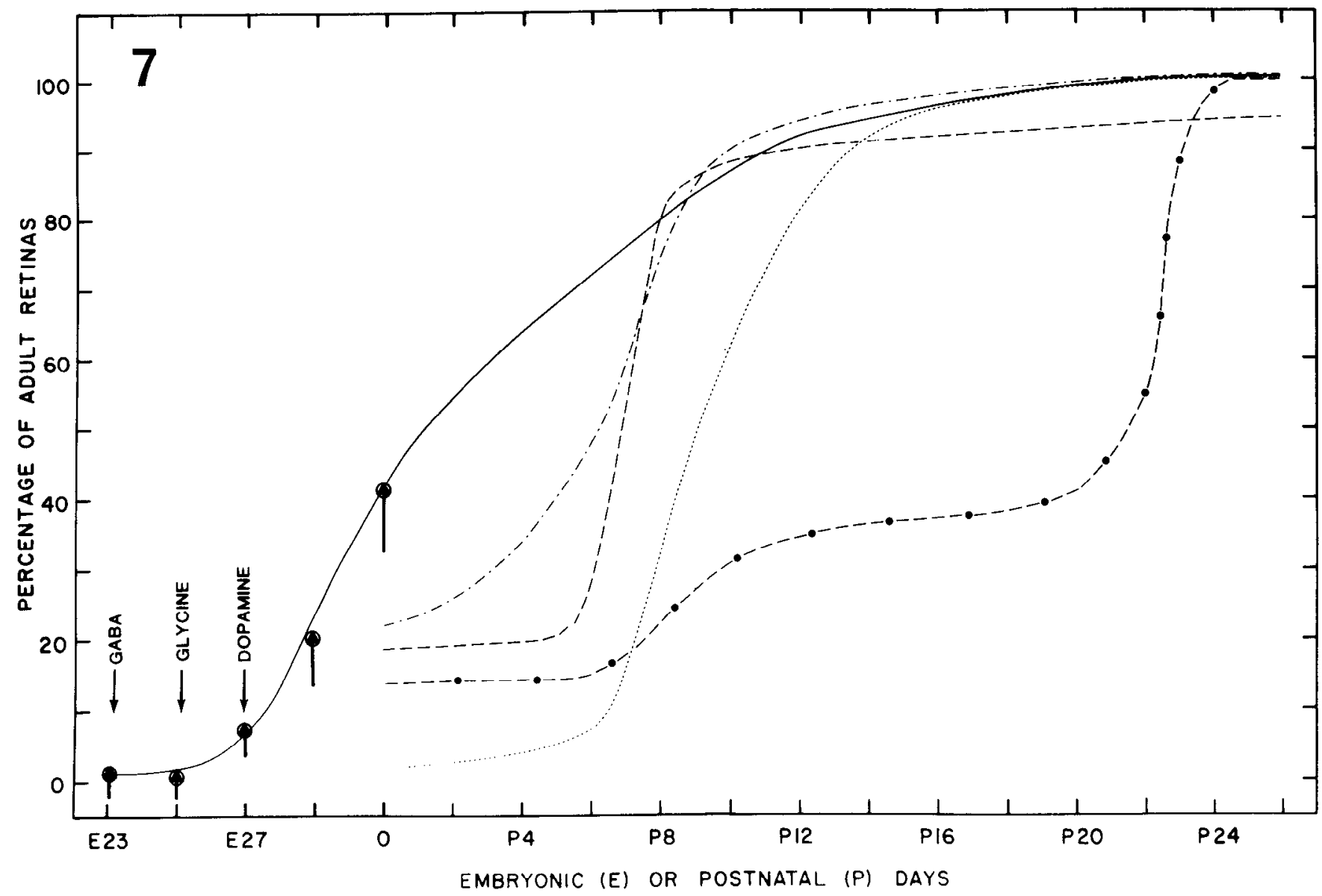

Figure 7. A summary of the prenatal and postnatal development of transmitter systems in the rabbit retina. All values are expressed as a percentage of adult retinas. Vertical arrows, The first time ( \pm day) at which specific GABA-, glycine-, and dopamine-accumulating cells can be observed under our experimental conditions; solid line, the developmental pattern of $\mathrm{K}^{+}$. stimulated, $\mathrm{Ca}^{2+}$-dependent $\left[{ }^{3} \mathrm{H}\right]$ dopamine release from the retina; solid circles, endogenous concentration of dopamine; dotted line, $\mathrm{K}^{+}$-stimulated, $\mathrm{Ca}^{2+}$-dependent release of $\left.\mathrm{I}^{3} \mathrm{H}\right]$ glycine; dashed-dotted line, endogenous concentrations of $\mathrm{GABA}$; dashed line, $\mathrm{K}^{+}$-stimulated $\mathrm{Ca}^{2+}$-dependent release of $\left[{ }^{3} \mathrm{H}\right] \mathrm{GABA}$. The mean values and standard errors of the prenatal $\left[{ }^{3} \mathrm{H}\right]$ dopamine release are indicated by circles and vertical bars. The data for postnatal $\left[{ }^{3} \mathrm{H}\right]$ dopamine release have already been published ( $\mathrm{I}$ am et al., 1981). 
showed that over $85 \%$ of the radioactivity released in response to $\mathrm{K}^{+}$-rich Ringer's solution and remained as $\left[{ }^{3} \mathrm{H}\right]$ dopamine. Our data thus suggest that, unlike the developments of GABAergic and glycinergic systems in which emergence of the uptake mechanisms precedes that of the presumably synaptic release mechanisms by many days, for the dopaminergic system in the rabbit retina, the specific uptake and release mechanisms both emerge at about E27.

\section{Discussion}

Neurotransmitters as developmental probes. During the past several years, we have used neurotransmitterspecific properties, such as uptake, content, synthesis, and release, as physiological and anatomical probes to follow the emergence and maturation of GABAergic, glycinergic, and dopaminergic neurons in the vertebrate retina. We have chosen retinas of rabbit (Lam et al., 1980, 1981; Kong et al., 1980) and Xenopus laevis (Hollyfield et al., 1979; Rayborn et al., 1981; Sarthy et al., 1981) for these studies so that the development of a mammalian retina can be compared with that of a nonmammalian retina. The rabbit retina was used because the physiology, anatomy, and synaptic chemistry of this retina is one of the most extensively studied among mammals. In addition, several aspects concerning the development of the rabbit retina have been examined using morphological and electrophysiological techniques (Bowe-Anders et al., 1975; McArdle et al., 1977; Masland, 1977; Dacheux and Miller, 1981a, b). The African clawed toad, Xenopus laevis, was chosen because (1) the various stages of its development are well characterized (Nieuwkoop and Farber, 1956), (2) methods for incubating embryonic eye rudiments in vitro have been established (Jacobson, 1967), and (3) embryos can be readily obtained throughout the year.

The main conclusion from our studies to date on the developments of rabbit and Xenopus retinas is that the appearance of specific neuronal properties follows a precise temporal pattern for each of the neurotransmitters studied. In particular, dopaminergic neurons in both retinas mature at a much later time than the putative GABAergic and glycinergic neurons (Sarthy et al., 1981; Lam et al., 1981). However, despite these general similarities in the developmental patterns of rabbit and Xenopus retinas, there are also intriguing differences. For instance, the temporal patterns by which dopaminergic properties emerge and mature are different for Xenopus and rabbit retinas (Sarthy et al., 1981; Lam et al., 1981). These results therefore indicate that, for some transmitters, development of the uptake, synthesis, and release mechanisms may follow different patterns in different retinas. An alternative hypothesis is that such variations in developmental patterns do not reflect directly on the nature or identity of the neurotransmitter but instead may be determined by the functional roles played by the transmitter-specific neuron and/or its position and ramification in the retina. This possibility is of particular interest because it is well known that the same neurotransmitter often is used by morphologically and functionally different types of neurons in different retinas. For instance, dopamine may be the transmitter for a subpopulation of amacrine cells in some retinas and for certain interplexiform cells in other retinas (Dowling and Ehinger, 1978a, b; Sarthy and Lam, 1979b). Likewise, although GABA has been shown to be the neurotransmitter used by a type of horizontal cells (H1) in the teleost retina (Lam et al., 1980), horizontal cells in most mammalian retinas probably do not use GABA as a neurotransmitter (Graham, 1974; Brandon et al., 1980). It is not known whether these diversities in transmitterspecific neuronal pathways among vertebrate retinas reflect merely the random choice of transmitters by retinal neurons or possess phylogenetic implications. Perhaps further studies on the development of transmitter systems may shed light on the synaptic chemical organization of the retina as well.

Mitosis and neuronal differentiation. One of the working hypotheses in neural development is that the expressions of neuron-specific properties generally follow the cessation of mitotic activities. A direct way to examine this hypothesis would be to determine simultaneously by autoradiography the birth dates of particular neurons using $\left[{ }^{3} \mathrm{H}\right]$ thymidine and the emergence of their transmitter uptake mechanisms using ${ }^{14} \mathrm{C}$ transmitter candidates. Since these studies are still in progress, we do not know yet whether, for GABAergic, glycinergic, and dopaminergic neurons in the rabbit retina, the high affinity uptake systems develop before or after mitotic activities in the neurons have been completed. However, in both rabbit and Xenopus retinas, we have failed to observe any dividing cell heavily accumulating labeled GABA, glycine, or dopamine, suggesting either that these uptake systems appear after the cessation of mitosis or that the transmitters are metabolized or released as rapidly as they are taken up.

Sites of transmitter uptake and release. For the dopamine system in the rabbit retina, our results show that the $\mathrm{K}^{+}$-stimulated, $\mathrm{Ca}^{2+}$-dependent release mechanism and the high affinity uptake mechanism both emerge around E27 (Fig. 7). The cellular locations of the uptake sites are not known and must await electron microscopy autoradiography and perhaps synaptosomal studies. It is, however, of interest that we have shown previously that, when isolated goldfish retinas were incubated with $\left[{ }^{3} \mathrm{H}\right]$ dopamine for various periods of time, the presynaptic terminals of the putative dopaminergic neurons are labeled much earlier than the corresponding somas (Sarthy and Lam, 1979b). In addition, on E27, when this uptake mechanism can be first demonstrated autoradiographically, the dopamine-accumulating cells of the rabbit retina already possess extensive processes and numerous punctate terminals (Fig. 4c). By E29, the dopaminergic processes form a distinct lamination in the inner plexiform layer (Fig. 6c). Taken together, these results suggest that the uptake sites for dopamine may be predominantly on the presynaptic terminals rather than on the somas of retinal dopaminergic neurons and that these sites may be present as early as E27 in the rabbit retina.

The cellular locations of the $\mathrm{K}^{+}$-stimulated, $\mathrm{Ca}^{2+}$-dependent sites for dopamine release also are not known. In analogy with similar studies in other intact nervous tissues and retinal synaptosomal preparations (Roberts et al., 1978; Thomas et al., 1978), it is likely that, under 
our experimental conditions, the release of dopamine originates from presynaptic sites on the dopaminergic neurons. Once again, electron microscopic autoradiography and synaptosomal studies of dopamine release in prenatal rabbit retinas are necessary to verify or refute this hypothesis and to examine further any possible interactions between dopamine uptake and release in the presynaptic terminals.

In contrast to the emergence of dopamine uptake and release, the emergence of the uptake mechanisms for GABA and glycine greatly precedes the appearance of the $\mathrm{K}^{+}$-stimulated, $\mathrm{Ca}^{2+}$-dependent release mechanisms. Several lines of evidence suggest that, contrary to dopaminergic neurons, somas of GABA- and glycine-accumulating cells possess high affinity uptake sites. The strongest evidence is that in the Xenopus retina, where the high affinity mechanisms for GABA and glycine uptake emerges much earlier than the formation of any morphologically identifiable synaptic terminals or contacts (Chen and Witkovsky, 1979; Hollyfield et al., 1979; Rayborn et al., 1981). In the rabbit retina, McArdle et al. (1977) have shown that the density of conventional synapses in the inner plexiform layer, which include the putative GABAergic and glycinergic synapses, increases dramatically from about the 7th postnatal day. If we assume that the release of GABA and glycine under our experimental conditions originates predominantly from the presynaptic GABAergic and glycinergic terminals, respectively, our results showing that the mechanisms for GABA and glycine release do not occur until about P7 are then consistent with the morphological maturation of synapse formations.

Maturation of GABAergic and glycinergic systems: Neurophysiological correlations. Besides morphological investigations, several elegant studies on the ontogeny of functional synapses in the rabbit retina using extracellular (Bowe-Anders et al., 1975; Masland, 1977) and intracellular (Dachuex and Miller, 1981a, b) recordings also have been reported. In sum, these investigators found that motion- and direction-selective receptive fields could be recorded from ganglion cells by about P10 or P11. Additionally, Caldwell et al. (1978) have shown that GABAergic amacrine cells in the adult rabbit retina probably are involved in the organization of directionselective receptive fields of ganglion cells. Our finding that, at 9 days of age, putative GABAergic neurons take up, synthesize, store, and release GABA at over $80 \%$ of the adult levels is therefore consistent with the electrophysiological results that certain ganglion cells probably receive GABAergic input by $\mathrm{P} 10$ or P11. Similarly, our studies also indicate that the glycinergic amacrine cells in the rabbit retina can be considered mature by about $\mathrm{P} 12$, a time at which receptive fields of ganglion cells are forming rapidly.

Maturation of the dopaminergic system. On the basis of responsiveness to light, concentric receptive field organizations as well as motion and direction selectivities, Bowe-Anders et al. (1975) and Masland (1977) concluded that the ganglion cell responses appear to be mature by about P20. In this regard, it is especially interesting that the endogenous content of dopamine in a P20 rabbit retina is less than $40 \%$ of the adult level (Fig. 7). In fact, the most dramatic increase in retinal dopamine concentration does not begin until about P21 and does not reach the adult level until P24. This somewhat surprising finding, in particular, raises a number of questions regarding the logistics in the development of retinal neurons and their transmitter systems. For instance, while it is logical and intuitively reasonable that GABAergic and glycinergic neurons mature before or around the time of eye opening (P10 to 11) and the formation of receptive fields in ganglion cells, it is puzzling that the dopaminergic neurons are not mature for another 2 weeks. This result is even more intriguing because the commitment by certain neurons to be dopaminergic, as determined by dopamine uptake and release, is apparently made by E27, almost 1 month earlier than the maturation of dopamine synthesis and content. Additionally, the increase in dopamine content and synthesis during retinal development follows a distinct biphasic pattern, suggesting that the onset of each phase may somehow be closely regulated. Moreover, in the Xenopus retina, dopaminergic neurons also mature many stages after the maturation of GABAergic and glycinergic neurons (Sarthy et al., 1981).

Our studies to date have led to a description of the developmental pattern for retinal dopaminergic systems. We have, however, gained little insight on the logistics of this development. This is to a large extent because we do not know yet the functional roles played by dopaminergic neurons and how they influence the processing of visual information in any retina, adult or embryonic. Several recent findings have raised the possibility that retinal dopaminergic neurons may not play a direct role in receptive field organizations of ganglion cells but instead may be mainly responsible for specific fine tunings or metabolic regulations of certain retinal cells, perhaps through the adenylate cyclase systems (Negishi and Drujan; 1978; Watling et al., 1980; Redburn et al., 1980).

Our finding that the formations of receptive fields precede and are apparently independent of the maturation of the dopaminergic system during retinal development is consistent with such a hypothesis. In this regard, an interesting speculation to consider is that, while retinal dopaminergic neurons play an integral role in the adult retina, for some as yet unknown reason, the dopamine content in the developing rabbit retina is deliberately kept at a low level during the critical periods (from about P7 to P20) when the majority of synaptic connections as well as receptive fields are formed. Experimental investigations along such avenues may not only lead to further understanding of the logistics underlying retinal development but also provide insight into the relationships between transmitter-specific pathways and the functional organization of the visual system.

\section{References}

Ames, A., III, and D. A. Pollen (1969) Neurotransmission in central nervous tissues: A study of isolated rabbit retina. $\mathrm{J}$. Neurophysiol. 32: 424-444.

Bowe-Anders, A., R. F. Miller, and R. Dacheux (1975) Development characteristics of receptive organization in the isolated retina-eyecup of the rabbit. Brain Res. 87: 61-65.

Brandon, C., D. M. K. Lam, and J. Y. Wu (1979) The $\gamma$ aminobutyric acid system in the rabbit retina: Localization 
by immunocytochemistry and autoradingraphy. Proc. Natl. Acad. Sci. U. S. A. 76: 3557-3561.

Brandon, C., D. M. K. Lam, Y. Y. T. Su, and J. Y. Wu (1980) Immunocytochemical localization of GABA neurons in the rabbit and frog retina. Brain Res. Bull. 5: 21-29.

Brunn, A., and B. Ehinger (1972) Uptake of the putative neurotransmitter, glycine into the rabbit retina. Invest. Ophthalmol. 11: 191-198.

Caldwell, J. H., N. W. Daw, and H. J. Wyatt (1978) Effects of picrotoxin and strychnine on rabbit retinal ganglion cells: Lateral interactions for cells with more complex receptive fields. J. Physiol. (Lond.) 276: 277-298.

Chen, F., and P. Witkovsky (1979) The formation of photoreceptor synapses in the retina of larval Xenopus. J. Neurocytol. 7: 721-740.

Chin, C. A., and D. M. K. Lam (1980) The uptake and release of $\left({ }^{3} \mathrm{H}\right]$-glycine in the retina. J. Physiol. (Lond.) 308: 185-195.

Dacheux, R. F., and R. F. Miller (1981a) An intracellular electrophysiological study of the ontogeny of functional synapses in the rabbit retina. I. Receptors, horizontal, and bipolar cells. J. Comp. Neurol. 198: 307-326.

Dacheux, R. F., and R. F. Miller (1981b) An intracellular electrophysiological study of the ontogeny of functional synapses in the rabbit retina. II. Amacrine cells. J. Comp. Neurol. 198: 327-334.

Dowling, J. E., and B. Ehinger (1978a) Synaptic organization of the dopaminergic neurons in the rabbit retina. J. Comp. Neurol. 180: 203-220.

Dowling, .I. F., and B. Fhinger (1978b) The interplexiform cell system. I. Synapses of the dopaminergic neurons of the goldfish retina. Proc. R. Soc. Lond. (Biol.) 210: 7-26.

Ehinger, B. (1970) Autoradiographic identification of rabbit retinal neurons that take up GABA. Experientia 26: 1063-1064.

Ehinger, B. (1977) Synaptic connections of the dopaminergic retinal neurons. Adv. Biochem. Psychopharmacol. 16: 299-306.

Ehinger, B., and I. Floren (1978) Quantitation of the uptake of indolamines and dopamine in the rabbit retina. Exp. Eye Res. 26: 1-11.

Graham, T. (1974) Comparative aspects of neurotransmitters in the retina. In The Eye, H. Dawson and L. T. Graham, eds., Vol. 6, pp. 283-342, Academic Press, New York.

Hildebrand, J. G., D. Barker, E. Herbert, and E. Kravitz (1971) Screening of neurotransmitters: A rapid radiochemical procedure. J. Neurobiol. 2: 221-246.

Hollyfield, J. G., P. V. Sarthy, M. E. Rayborn, and D. M. K. Lam (1979) The emergence, localization and maturation of neurotransmitter system during development of the retina in Xenopus laevis. I. $\gamma$-Aminobutyric acid. J. Comp. Neurol. 188: 587-598.

Jacobson, A. G. (1967) Amphibian cell culture, organ culture and tissue dissociation. In Methods in Developmental Biology, F. H. Wilt and N. K. Wessells, eds., pp. 531-542, Thomas H. Crowell Co., New York.

Kolb, H. (1979) The inner plexiform layer in the retina of the cat: Electron microscopic observations. J. Neurocytol. 8: 295-329.
Kolb, H., and E. V. Famiglietti (1974) Rod and cone pathways in the inner plexiform layer of cat retina. Science 186: $47-49$.

Kong, Y. -C., S. -C. Fung, and D. M. K. Lam (1980) The postnatal development of glycinergic neurons in rabbit retina. J. Comp. Neurol. 193: 1127-1135.

Lam, D. M. K., Y. Y. T. Su, L. Swain, R. E. Marc, C. Brandon, and J. Y. Wu (1979) Immunocytochemical localization of glutamic acid decarboxylase in the goldfish retina. Nature 278: $565-567$

Lam, D. M. K., S. -C. Fung, and Y. -C. Kong (1980) The postnatal development of GABA-ergic neurons in the rabbit retina. J. Comp. Neurol. 193: 89-102.

Lam, D. M. K., S. -C. Fung, and Y. -C. Kong (1981) Postnatal development of dopaminergic neurons in the rabbit retina. $\mathrm{J}$. Neurosci. 1: 1117-1132.

Masland, R. H. (1977) Maturation of function in the developing rabbit retina. J. Comp. Neurol. 175: 275-286.

McArdle, C. B., J. E. Dowling, and R. E. Masland (1977) Development of outer segments and synapses in the rabbit retina. J. Comp. Neurol. 175: 253-274.

Negishi, D., and B. D. Drujan (1978) Effects of catecholamines on the horizontal cell membrane potential in the fish retina. Sens. Processes 2: 388-395.

Nieuwkoop, P. D., and J. Farber (1956) Normal Tables of Xenopus laevis (Daudin), North-Holland Publishing Co., Amsterdam

Rayborn, M. E., P. V. Sarthy, D. M. K. Lam, and J. G. Hollyfield (1981) The emergence, localization and maturation of neurotransmitter system during development of the retina in Xenopus laevis. II. Glycine. J. Comp. Neurol. 195: 585-594.

Redburn, D. A., Y. Clement-Cormier, and D. M. K. Lam (1980) GABA and dopamine receptor binding in retinal synaptosomal fractions. Neurochemistry 1: 167-182.

Rieske, E., P. Schubert, and G. W. Kreutzberg (1975) Transfer of radioactive materials between electrically coupled neurons of the leech central nervous system. Brain Res. 84: 365-382.

Roberts, P. J., G. N. Woodruff, and L. L. Iversen (1978) Dopamine. Adv. Biochem. Psychopharmacol, 19.

Sarthy, P. V., and D. M. K. Lam (1979a) Isolated cells from a mammalian retina. Brain Res. 176: 208-212.

Sarthy, P. V., and D. M. K. Lam (1979b) The uptake and release of $\left({ }^{3} \mathrm{H}\right)$ dopamine in the goldfish retina. J. Neurochem. 32: $1269-1277$.

Sarthy, P. V., M. E. Rayborn, J. G. Hollyfield, and D. M. K. Lam (1981) The emergence, localization and maturation of neurotransmitter system during development of the retina in Xenopus laevis. III. Dopamine. J. Comp. Neurol. 195: 595-603.

Thomas, T. N., Y. Clement-Cormier, and D. A. Redburn (1978) Uptake and release of $\left({ }^{3} \mathrm{H}\right)$ dopamine and dopamine-sensitive adenylate cyclase in retinal synaptosomal fractions. Brain Res. 155: 391-396.

Watling, K., J. E. Dowling, and L. L. Iversen (1980) Dopaminergic mechanisms in the carp retina: Effects of dopamine, $\mathrm{K}^{+}$and light on cyclic AMP synthesis. Neurochemistry 1: $519-537$. 